\title{
Improving the Thermal Comfort of a Building by Adding a Layer of Straw over the High Floor
}

\author{
Gollé Diouf', Oumar Diallo²*, Harouna Mamadou Bal², Pape Moussa Toure³, Salif Gaye² \\ ${ }^{1}$ GSSSM, Faculté des Sciences, Université Cheikh Anta DIOP de Dakar, Dakar, Sénégal \\ ${ }^{2}$ Laboratoire des Matériaux et d'Energétique de l'IUT, Université de Thiès, Thiès, Sénégal \\ ${ }^{3}$ LEA, Ecole Supérieure Polytechnique, Université Cheikh Anta DIOP de Dakar, Dakar, Sénégal \\ Email: *ou.diallo@univ-thies.sn
}

How to cite this paper: Diouf, G., Diallo, O., Bal, H.M., Toure, P.M. and Gaye, S. (2020) Improving the Thermal Comfort of a Building by Adding a Layer of Straw over the High Floor. Journal of Building Construction and Planning Research, 8, 193-202. https://doi.org/10.4236/jbcpr.2020.83012

Received: May 26, 2020

Accepted: September 20, 2020

Published: September 23, 2020

Copyright $\odot 2020$ by author(s) and Scientific Research Publishing Inc. This work is licensed under the Creative Commons Attribution International License (CC BY 4.0).

http://creativecommons.org/licenses/by/4.0/

\section{Open Access}

\begin{abstract}
This document deals with the thermal characterization of a building with a layer of straw above the high floor. In the current environmental context, in Senegal, buildings are the biggest consumers of energy. This is due to the construction materials used. Almost of buildings in Senegal used concrete (cement + aggregates) as based material construction. Due to this, the buildings require air conditioning or artificial ventilation to ensure minimum comfort. In face of this situation, it becomes useful to propose methods for reducing this high energy consumption. In this work, we propose to add a layer of straw above the high floor of a building in Matam city (North Senegal). In this case, we designed and modeled one building of single room in which the walls are in briks and a concrete slab. A bale of straw is layered on this slab in order to determine its influence on the energy consumption of the building. This study shows that the straw has a strong influence on the energy consumption of a building and the slab + straw building is more energy efficient than the bare slab building.
\end{abstract}

\section{Keywords}

Thermal Comfort, Energy, Building, Straw

\section{Introduction}

The question of the rational use of energy has been imposed in recent years, with the aim of opposing the increase in its cost and the disastrous consequences on the environment. These energy and environmental challenges have motivated industrialized countries to consider seriously the issue. Many organizations, forums and panels are working on the energy and the importance of its control. Air conditioning systems consume large amounts of energy to ensure conditions 
of thermal comfort inside buildings. Thus, the reduction in the consumption of energy resources from fossil sources and the reduction in the rate of pollution in the air oblige us to create buildings, which provide us more thermal comfort without resorting to air conditioning, which consumes a lot of energy. Then the researchers investigate the problem of heat exchange between the premises and the environment. Insulation is one of the main axes of bioclimatic architecture; it simultaneously increases comfort and reduces air conditioning energy consumption. However, that is not all; insulation is also beneficial for the environment because, by reducing consumption, it conserves energy resources and limits greenhouse gas emissions. Thermal insulation is therefore attractive in terms of comfort, financial savings and environmental protection [1]. However, the absence of detailed data on thermo-physical properties can lead to operational anomalies. Our study aims to carry out a scientific review of a local material for building, to deal with these anxieties which have just been listed. We propose to layer straw, which is used as a building material in rural areas in particular, above the high floor.

\section{Mathematical Model}

The modeling of the thermal load in a confined space aims to predict mass and heat transfers from the outside to the inside of this space during the summer. There are thus three modes of heat transmission: conduction, convection and radiation [2]. Establishing the heat balance in a space consists of determining or evaluating all of the thermal loads to be removed for a 24-hour time base. The hourly load of the building is mainly a function of the following parameters: latitude, longitude, altitude, orientation, dry and wet ambient temperatures, atmospheric pressure, wind speed and direction, sunshine, the size of the shaded external surfaces, opacity of the walls, the thickness of the walls, the conductivity of the walls, of the occupants, the lighting, the infiltrations [3]. In this work, we are only interested in the contribution of heat flow through the slab. Whatever the regime (permanent or dynamic), we obtain it by the following relation:

$$
\varphi=\frac{T_{e}-T_{i}}{R_{t h}}
$$

with

$$
R_{t h}=\frac{1}{h_{i}}+\sum_{j=1}^{n} \frac{e_{j}}{\lambda_{j} S}+\frac{1}{h_{e}}
$$

In our study, we have two variants (Figure 1 and Figure 2): concrete slab only and concrete slab with straw layer.

By applying relation (2) on the diagrams of Figure 1 and Figure 2; we obtain respectively:

$$
R_{t h 1}=\frac{1}{h_{i}}+\frac{e_{c s}}{\lambda_{c s} S}+\frac{1}{h_{e}}
$$

and 


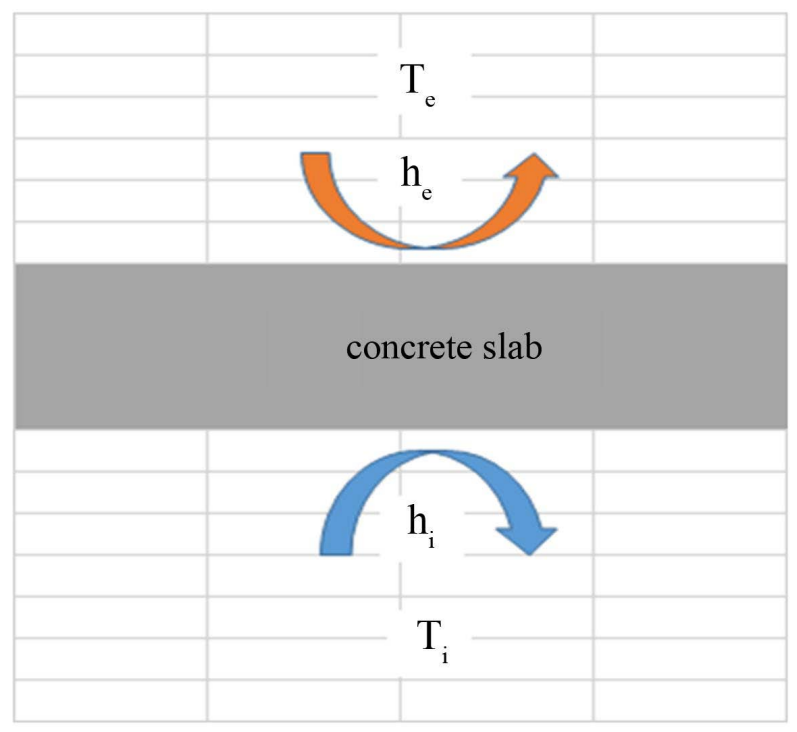

Figure 1. Concrete slab.

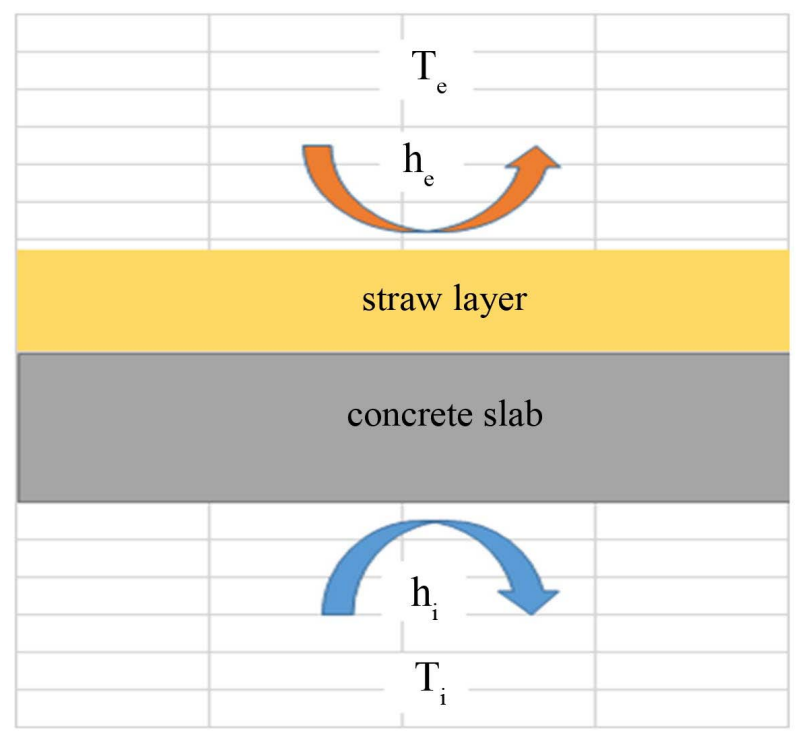

Figure 2. Concrete slab + straw layer.

$$
R_{t h 2}=\frac{1}{h_{i}}+\frac{e_{c s}}{\lambda_{c s} S}+\frac{e_{s l}}{\lambda_{s l} S}+\frac{1}{h_{e}}
$$

\section{Parameters Estimation}

The straw used in this study is part of the family of proaceae and the genus pennisetum found in abundance in this study area. This straw is generally used in Senegal for the construction of thatched roofs in rural areas. The photos in Figure 3 show the appearance of this straw in fibbers (a) and after preparation (b).

The technique for measuring thermal conductivity of the straw used in this work is called the "box method" (Figure 4). It is installed at the Applied Energy 


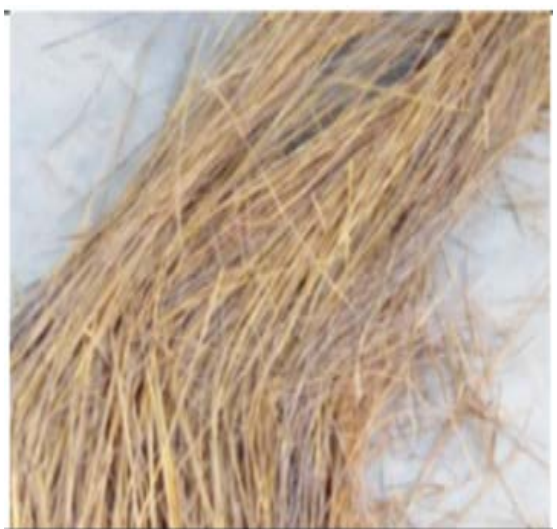

(a)

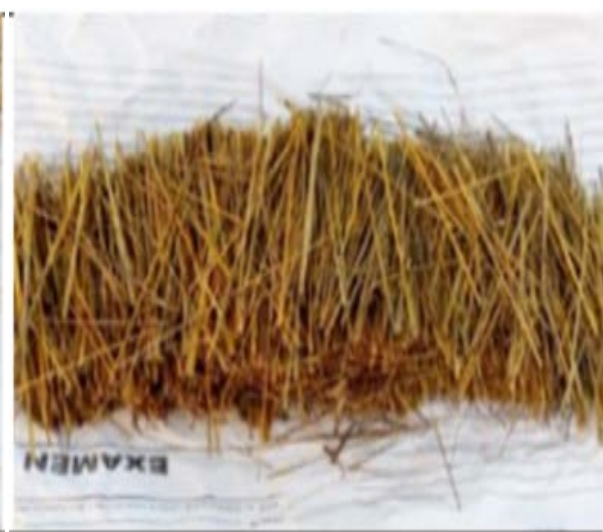

(b)

Figure 3. Physical appearance of straw.

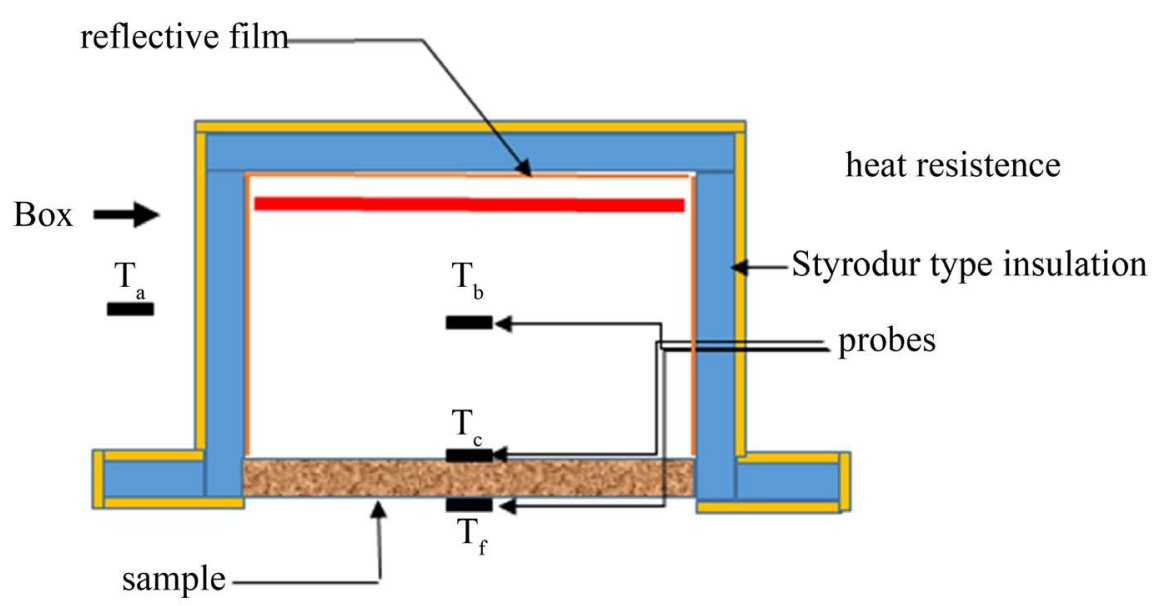

Figure 4. Box for measurement of thermal conductivity and position of probes.

Laboratory (LEA) of the École Supérieure Polytechnique (ESP) in Dakar. Furthermore, the measurements are made more or less under the actual conditions of use of the material. It has been used successfully by various authors including [4] [5] [6].

According to the principle of energy conservation, the heat flux given off by the heating film will on the one hand be transmitted by conduction through the sample, and on the other hand lost through the side walls, this leads us to the following equality:

$$
\lambda=\frac{e}{S\left(T_{c}-T_{f}\right)}\left[\frac{V^{2}}{R}-C\left(T_{b}-T_{c}\right)\right]
$$

The loss coefficient $(C)$ characterizes the heat losses through the side walls of the boxes due to the presence of a temperature gradient between the inside of the boxes and the outside atmosphere. Theoretically, it is determined using the formulas of Carslaw and Jager [7] which make it possible to determine the thermal flows through a dihedral in steady state, and those of Langmuir [8], giving the values of the form coefficient for a corner. For boxes with Styrodur as insulation 
and plywood as external cover, the numerical application of these formulas [9], gives us $C=0.19$.

In this measurement study, we carried out two tests and the values of the temperatures and voltages recorded when the steady state is reached are indicated in Table 1.

The injection of the values of these two arrays into the relation (5) allows us to obtain: $\lambda_{1}=0.076$ et $\lambda_{2}=0.050$. The average of the two values of the conductivity: $\lambda_{\text {mean }}=0.063 \mathrm{~W} \cdot \mathrm{m}^{-1} \cdot \mathrm{K}^{-1}$. Even if the difference between the two experimental values is quite large, we note that the average value is fairly close to an indication in the literature [10].

For the measurement of the thermal conductivity of the concrete slab, it was envisaged to use the asymmetric hot plane method. However, the sample representing the slab is problematic because the slab is generally made up of hollow bricks and other aggregates. Some literature data indicate that for a solid concrete whose density value is between 1700 and $1900 \mathrm{~kg} / \mathrm{m}^{3}$, the thermal conductivity value varies from 0.8 to $1.75 \mathrm{~W} \cdot \mathrm{m}^{-1} \cdot \mathrm{K}^{-1}$ [11]. For calculation purposes, we have set the upper limit value.

\section{Calculation of Energy Consumption}

\subsection{Methodology}

The energy consumption linked to the search for comfort in the home currently poses many financing problems in households and in particular in rural areas. In these areas, especially in the Matam region (northern Senegal), the temperature is very hot during certain periods (May, June), as shown by the temperature data diagram in the area in Table 2.

The problem is much more difficult for the latter because most of them live abroad and build so-called modern habitats, the envelope of which is made of concrete and therefore unsuitable for periods of heat. To estimate the energy consumption, it is sufficient for each case to determine the heat flow transferred through the slab (bare or with straw layer). The capacity of the refrigerating machine to extract this transferred heat per unit of operating time corresponds

Table 1. Experimental values recorded at the first and second steady state test.

\begin{tabular}{ccccccccc}
\hline Parameters & $T_{f}$ & $T_{c}$ & $T_{a}$ & $T_{b}$ & $V($ Volt $)$ & $R($ Ohms $)$ & $T_{c}-T_{f}$ & $T_{b}-T_{a}$ \\
\hline Test 1 & 18.44 & 25.76 & 30.14 & 30.23 & 14.89 & 266.00 & 7.32 & 0.09 \\
Test 2 & 17.53 & 24.18 & 27.76 & 28.30 & 12.53 & 266.00 & 6.65 & 0.54 \\
\hline
\end{tabular}

Table 2. Average monthly temperatures in the Matam region.

\begin{tabular}{ccccccccccccc}
\hline TEMP $\left({ }^{\circ} \mathrm{C}\right)$ & JAN & FEB & MAR & APR & MAI & JUN & JUL & AUG & SEPT & OCT & NOV & DEC \\
\hline Mean-Min & 15.5 & 17.3 & 20.1 & 23.5 & 26.1 & 27.2 & 25.6 & 24.5 & 24.4 & 23.8 & 19.7 & 17 \\
Mean-Max & 33.5 & 36.4 & 38.7 & 41.1 & 42.5 & 40.9 & 36.7 & 34.6 & 35.4 & 38.4 & 37 & 33.8 \\
Mean & 24.5 & 26.8 & 29.4 & 34.3 & 34.3 & 34 & 31.1 & 29.5 & 29.9 & 31.1 & 28.3 & 25.4 \\
\hline
\end{tabular}


in absolute value to its refrigerating capacity. The power absorbed by this machine can be obtained if we know the coefficient of performance. Thus, the electrical power is calculated by estimating the coefficient of performance of the compressor and we deduce the following:

$$
C O P=\frac{\varphi}{P a} \text { ou } P a=\frac{\varphi}{C O P}
$$

The annual energy consumption is equal to the product absorbed by the compressor operating time according to:

$$
C_{e-a}=\text { Pat }_{o}
$$

By replacing with the above, we obtain for any type of wall:

$$
C_{e-a}=\frac{T_{e x t}-T_{i n t}}{\frac{1}{h_{i}}+\sum_{j=1}^{n} \frac{e_{j}}{\lambda_{j} S}+\frac{1}{h_{e}}} \cdot \frac{t_{o}}{C O P}
$$

\subsection{Steady State}

In our case, we are studying in particular the contribution to the energy consumption of the upper slab. Matam has a desert climate (BWh) according to the KÖPPEN-GEIGER classification and over the year. The average temperature in the studied area is $30.6^{\circ} \mathrm{C}$ with a relative humidity $(\mathrm{RH})$ which can reach $65 \%$ during the rainy season. The internal thermo-hygrometric conditions are fixed as follows: $24^{\circ} \mathrm{C}$ and $50 \% \mathrm{RH}$. The room studied is an administrative building which is open from 8 a.m. to 6 p.m. and Monday to Friday, i.e. 50 hours/week, which corresponds to 2600 hours annually. The heat exchange resistance of the internal surface $r_{s i}$ and that of the external surface $r_{s e}$ are taken from the literature equal to 0.17 and $0.05 \mathrm{~m}^{2} \cdot \mathrm{K} \cdot \mathrm{W}^{-1}$ respectively for a horizontal wall [12]. The value of this surface heat exchange resistance depends on the inclination of the wall and the internal one is always greater than the external value because the air movements are greater outside than inside, which influences convective heat transfer.

- Concrete slab alone

By numerical application of the previous Equation (3), we obtain with Table 3 , the value of the contribution of the concrete slab on the annual energy consumption which is $30.2 \mathrm{kWh}$.

- Concrete slab and straw

For the concrete Slab combined to straw layer, we obtain in Table 4, the annual energy consumption which is $14.4 \mathrm{kWh}$.

By distributing the annual operating time over the 12 months, we draw the curve of electrical power consumed in steady state as well for the bare slab as for the slab covered with a layer of straw, Figure 5.

These results show that the energy consumption which was $12 \mathrm{~kW}$ for concrete slab only is reduced to approximately $6 \mathrm{~kW}$ for concrete slab with straw. Layering the straw one the concrete slab contributes to reduction of energy 
Table 3. Energy consumption due to the concrete slab in steady stage.

\begin{tabular}{cccccccc}
\hline$e_{1}(\mathrm{~m})$ & $\lambda_{1}\left(\mathrm{~W} \cdot \mathrm{m}^{-1} \cdot \mathrm{K}^{-1}\right)$ & $S\left(\mathrm{~m}^{2}\right)$ & $e_{1} /\left(\lambda_{1} \mathrm{~S}\right)$ & & $r_{s i}=1 / h_{i}$ & $r_{s i}=1 / h_{i}$ & $R_{t h}$ \\
\hline 0.2 & 1.75 & 16 & 0.007 & & 0.17 & 0.05 & 0.2271 \\
$T_{m-\text { ext }}$ & $T_{m-\text { ixt }}$ & $\Delta T$ & $\phi_{1}(\mathrm{~W})$ & $C O P$ & $P_{a}(\mathrm{~W})$ & $t_{f}(\mathrm{~h})$ & $\mathrm{C}_{e-a}(\mathrm{~kW} \cdot \mathrm{h})$ \\
30.6 & 24 & 6.6 & 29.06 & 2.5 & 11.6 & 2600 & 30.2 \\
\hline
\end{tabular}

Table 4. Energy consumption due to the concrete slab + straw layer in steady stage.

\begin{tabular}{cccccccc}
\hline$e_{1}(\mathrm{~m})$ & $\lambda_{1}\left(\mathrm{~W} \cdot \mathrm{m}^{-1} \cdot \mathrm{K}^{-1}\right)$ & $S\left(\mathrm{~m}^{2}\right)$ & $\mathrm{e}_{1} /\left(\lambda_{1} S\right)$ & & $r_{s i}=1 / h_{i}$ & $r_{s i}=1 / h_{i}$ & $R_{\text {th }}^{\prime}$ \\
\hline 0.20 & 1.75 & 16 & 0.007 & & 0.17 & 0.05 & 0.4752 \\
$e_{2}(\mathrm{~m})$ & $\lambda_{2}\left(\mathrm{~W} \cdot \mathrm{m}^{-1} \cdot \mathrm{K}^{-1}\right)$ & $S\left(\mathrm{~m}^{2}\right)$ & $\mathrm{e}_{2} /\left(\lambda_{2} S\right)$ & & & & \\
0.25 & 0.06 & 16 & 0.248 & & & & \\
$T_{m-\text { ext }}$ & $T_{m-\text { xxt }}$ & $\Delta T$ & $\phi_{2}(\mathrm{~W})$ & $C O P$ & $P_{a}(\mathrm{~W})$ & $t_{f}(\mathrm{~h})$ & $\mathrm{C}_{\text {e-a }}(\mathrm{kW} \cdot \mathrm{h})$ \\
30.6 & 24.0 & 6.6 & 13.89 & 2.5 & 5.6 & 2600 & 14.4 \\
\hline
\end{tabular}

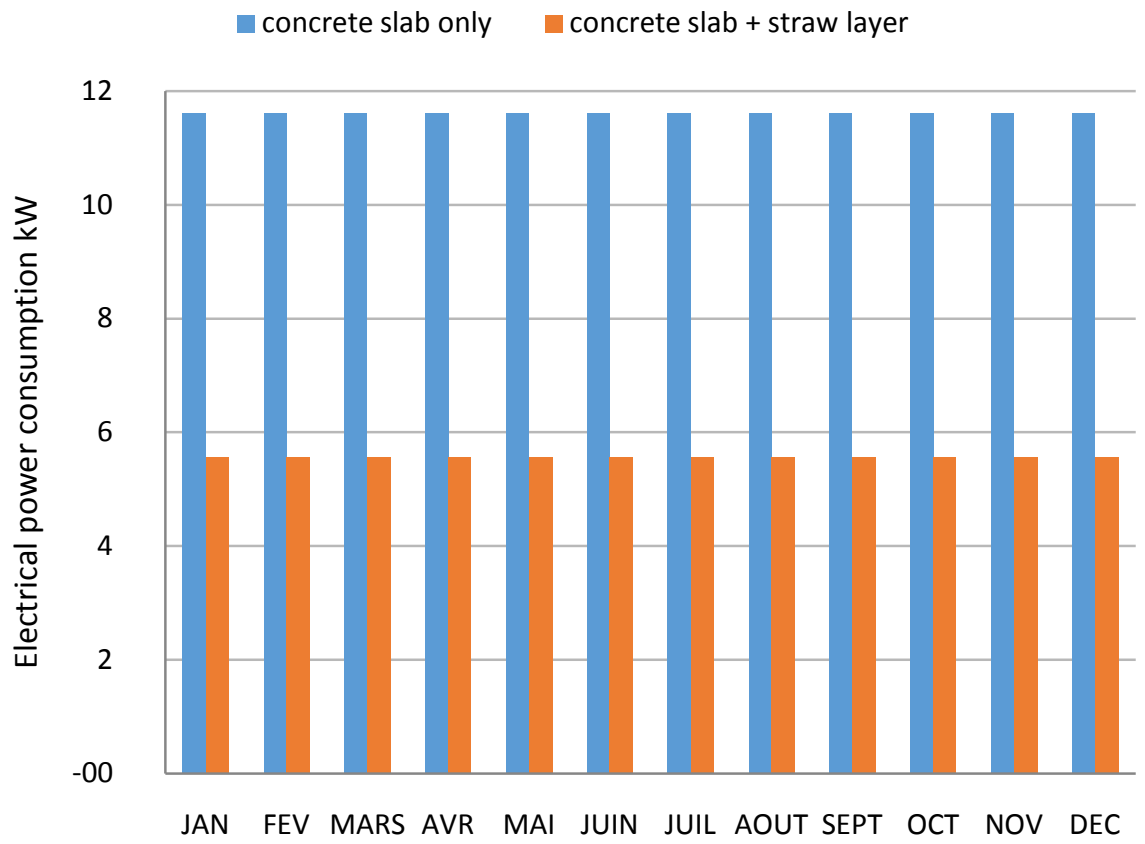

Figure 5. Electrical Power consumption in steady stage.

charges. This is benefits for the customers and the national energy distribution because it will participate to reduce the load shedding.

\section{Dynamic State}

Calculating steady state energy consumption does not reflect reality well. Indeed, there are very important variations of the temperature during the year. By setting the value of this average temperature under certain conditions, there is a risk of oversizing or doing the opposite. So, instead of starting on an annual average, we will use the monthly averages, Table 5.

Starting from the heat flow for each month where the average temperature is 
Table 5. Monthly consumption in $\mathrm{kW} \cdot \mathrm{h}$ for concrete slab comparing to concrete slab with straw layer.

\begin{tabular}{ccccccccccccc}
\hline Month & JAN & FEV & MARS & AVR & MAI & JUIN & JUIL & AOUT SEPT & OCT & NOV & DEC \\
\hline Conc Slab & 0.19 & 1.07 & 2.05 & 3.16 & 3.92 & 3.80 & 2.70 & 2.09 & 2.24 & 2.70 & 1.64 & 0.53 \\
$\begin{array}{l}\text { Conc Slab } \\
+ \text { Straw }\end{array}$ & 0.42 & 2.36 & 4.55 & 6.99 & 8.67 & 8.42 & 5.98 & 4.63 & 4.97 & 5.98 & 3.62 & 1.18 \\
\hline
\end{tabular}

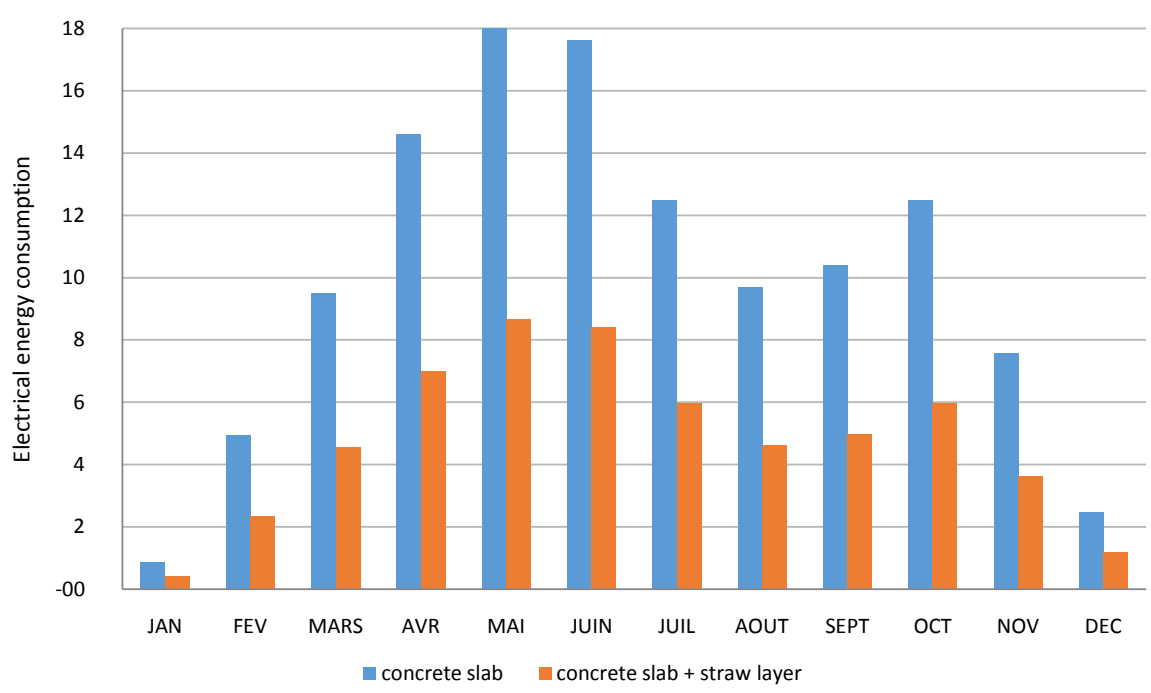

Figure 6. Electrical power consumption in dynamic stage.

assumed to be constant, we draw the curve representing electrical power as a function of time, Figure 6 .

The study in dynamic mode shows that the electric power required to maintain the room at $24^{\circ} \mathrm{C}$ varies according to the seasons. This is due to the fact that the losses are less important when the temperature difference is small.

\section{Conclusions}

In the work, we have studied the thermal properties of the straw in order to use it in construction in northern Senegal. This straw is added over the high floor. We designed a one-piece building made of a reinforced concrete slab made of cellular bricks.

In this work:

- The thermal load was first modelled in order to determine the contribution of the slab relative to this load.

- We have made a bibliographic review of the various measurements of thermal properties in order to choose those which make it possible to determine the parameters necessary for calculating the heat flux.

- Knowledge of the modelling of these methods made it possible to prepare the methodology and the measures to be taken to arrive at a correct estimate of the parameters.

- We have shown through this document that whatever the regime (permanent 
or dynamic) that the addition of a layer of straw on a concrete slab reduces very significantly ( $50 \%$ in our case) heat transfer.

In further work:

- We wish to make a study by ENERGYPLUS or TRANSYS to better refine the calculation of energy consumption in dynamic stage.

- We also want to make an optimization study on the thicknesses of straw to be superimposed on the concrete slab for fixed thickness.

\section{Conflicts of Interest}

The authors declare no conflicts of interest regarding the publication of this paper.

\section{References}

[1] Gibilisco, S. (2007) Alternative Energy. McGraw-Hill Companies, New York.

[2] Jannot (2012) Cours de Transfert de chaleur. Ecole des Mines de Nancy.

[3] Faye, et al. (2020) Contribution of an External Wall to the Thermal Load of a Building. Journal of Scientific and Engineering Research, 7, 197-206.

[4] El Bakkourri, A., et al. (2000) Méthode générale d'identification paramétrique: Application à l'étude thermophysique de quelques matériaux locaux utilisés dans la construction au Maroc (platre-liège-brique creuse). Canadian Journal of Civil Engineering, 27, 628-631. https://doi.org/10.1139/100-011

[5] Ezbakhe, H., et al. (2001) Etude thermique de terre stabilisée au ciment utilisée en construction au nord du Maroc. Rev. Energ. Ren.: Journées de Thermique, 69-72.

[6] Meukam, P., et al. (2004) Thermo Physical Characterstics of Economical Building Materials. Construction and Building Materials, 18, 437-443. https://doi.org/10.1016/j.conbuildmat.2004.03.010

[7] Carslaw and Jaeger (1959) Conduction of Heat in Solids. 2nd Edition, Oxford-Press, Oxford, Chap. XVI.

[8] Languimir, et al. (1913) Flow of Heat through Furnace Walls. Transactions of the American Electrochemical Socity, 53-61.

[9] Bourdilon, C. (2001) Notion de base sur les incertitudes et le traitement des données expérimentales en physique, chimie et biologie.

[10] CSTB (2003) Centre Scientifique et Technique du Bâtiment. Rapport annuel, Tome 2.

[11] Recknagel, S. (1998) Manuel pratique du génie climatique. Tome 2, Editions PYC.

[12] N'guessan, K.R. (1989) Contribution à l'étude en convection naturelle du comportement aéro-thermiques d'une cellule type pièce d'habitation. Université Paul Sabatier, Toulouse. 


\section{Nomenclature}

\begin{tabular}{|c|c|c|c|c|c|}
\hline \multicolumn{2}{|c|}{ Symbols: } & \multirow{2}{*}{$\begin{array}{l}C \\
t\end{array}$} & \multirow{2}{*}{$\begin{array}{l}\text { Loss coef. of boxes } \\
\text { Time, } \mathrm{h}\end{array}$} & \multirow{2}{*}{$\begin{array}{l}\text { th } \\
j\end{array}$} & \multirow{2}{*}{$\begin{array}{l}\text { thermal } \\
\text { layer number }\end{array}$} \\
\hline$S$ & surface of element, $\mathrm{m}^{2}$ & & & & \\
\hline$T$ & temperature, ${ }^{\circ} \mathrm{C}$ & \multicolumn{2}{|c|}{$C O P$ Coef. of performance } & $n$ & number of layer \\
\hline$e$ & thikness, $\mathrm{m}$ & $W$ & Energy consumption, $\mathrm{kW} \cdot \mathrm{h}$ & $B$ & box \\
\hline$V$ & Voltage, V & \multicolumn{2}{|c|}{ Greek Letters: } & $A$ & ambient \\
\hline$R$ & Electrical resistance, $\Omega$ & $\lambda$ & thermal conductivity, $\mathrm{W} \cdot \mathrm{m}^{-1} \cdot \mathrm{K}^{-1}$ & $C$ & hot contact \\
\hline$R^{\prime}$ & Resistance, $\mathrm{K} \cdot \mathrm{W}^{-1}$ & $\varphi$ & heat flux, $\mathrm{W}$ & $F$ & cold contact \\
\hline$P$ & Electrical Power, W & \multicolumn{2}{|c|}{ Indices/Exponents: } & $a$ & absorbed \\
\hline \multirow{2}{*}{\multicolumn{2}{|c|}{$\begin{array}{l}h \quad \text { isothermal convection } \\
\text { coef., } \mathrm{W} \cdot \mathrm{m}^{-2} \cdot \mathrm{K}^{-1}\end{array}$}} & $i$ & internal & $o$ & operating \\
\hline & & $e$ & external & an & annual \\
\hline
\end{tabular}

